\title{
Optimization of $\mathrm{CO}_{2}$ Absorption Characteristic under the Influence of $\mathrm{SO}_{2}$ in Flue Gas by Hollow Fiber Membrane Contactor
}

\author{
Ziyi Qu, ${ }^{1,2,3}$ Li Zhang, ${ }^{1,2}$ Yunfei Yan, ${ }^{1,2}$ and Shunxiang Ju ${ }^{1,2}$ \\ ${ }^{1}$ Key Laboratory of Low-Grade Energy Utilization Technologies and Systems, Ministry of Education, \\ Chongqing University, Chongqing 400030, China \\ ${ }^{2}$ College of Power Engineering, Chongqing University, Chongqing 400030, China \\ ${ }^{3}$ Chongqing Electric Power College, Jiulongpo District, Chongqing 400053, China \\ Correspondence should be addressed to Li Zhang; lizhang@cqu.edu.cn
}

Received 9 August 2016; Accepted 6 November 2016

Academic Editor: Naoki Haraguchi

Copyright (C) 2016 Ziyi Qu et al. This is an open access article distributed under the Creative Commons Attribution License, which permits unrestricted use, distribution, and reproduction in any medium, provided the original work is properly cited.

\begin{abstract}
Hollow fiber membrane contactor is a new, highly efficient, and the most promising technology for $\mathrm{CO}_{2}$ absorption in flue gas. There is still $\mathrm{SO}_{2}$ that exists in the flue gas after desulfurization tower of power plant. This paper studied the influence of $\mathrm{SO}_{2}$ on $\mathrm{CO}_{2}$ absorption characteristic in flue gas by hollow fiber membrane contactor with absorbent of EDA, EDA + MEA (0.6: 0.4), and $\mathrm{EDA}+\mathrm{MEA}+\mathrm{PZ}(0.4: 0.4: 0.2)$. The influences of $\mathrm{SO}_{2}$ concentration, cycle absorption and desorption characteristic of absorbent, absorbent concentration, and liquid-gas flow rate ratio are studied to analyze the influence of $\mathrm{SO}_{2}$ on $\mathrm{CO}_{2}$ absorption characteristic. The appropriate absorbent composition ratio and appropriate parameter range that can inhibit the influence of $\mathrm{SO}_{2}$ are proposed by studying the hybrid sorbent with activating agent, appropriate absorbent concentration, and ratio of liquid-gas flow rate. Among the three kinds of absorbents, EDA + MEA + PZ $(0.4: 0.4: 0.2)$ had the best tolerance ability to $\mathrm{SO}_{2}$ and the highest efficiency. With comprehensive consideration of $\mathrm{CO}_{2}$ removal efficiency and operating cost, under the condition of 1000 ppm $\mathrm{SO}_{2}$, the appropriate concentration and liquid-gas flow rate ratio of EDA, EDA + MEA, and EDA + MEA + PZ are proposed.
\end{abstract}

\section{Introduction}

In recent years, energy consumption has been increasing with the rapid growth of the world economy. The greenhouse effect of $\mathrm{CO}_{2}$ became increasingly serious, and hence energy conservation is urgent [1]. The hollow fiber membrane contactor is a new technology for the $\mathrm{CO}_{2}$ absorption process [2]. The membrane does not participate in the reaction, which isolates gas and liquid. In a hollow fiber membrane contactor, the absorbent flows in one side while the flue gas flows in the other side. The flue gas diffuses through the gas-liquid interface initially, and then $\mathrm{CO}_{2}$ reacts with the absorbent. Because of the $\mathrm{CO}_{2}$ concentration gradient in the gas and liquid phases, $\mathrm{CO}_{2}$ transfers from the gas phase to liquid phases through the membrane pores and continues to react with the absorbent. Because of the high reaction rate, simple operation, small volume membrane absorption technology, and low cost, the hollow fiber membrane contactor is one of the most promising decarburization technologies.

The alcohol amine absorbent used in $\mathrm{CO}_{2}$ absorption has been used in $\mathrm{SO}_{2}$ removal by many researchers [3-8]. The hollow fiber membrane contactor is not only applied for $\mathrm{CO}_{2}$ removal, but also applied to remove $\mathrm{SO}_{2}$. Ogundiran et al. [9] studied $\mathrm{SO}_{2}$ capture in flue gas by porous hydrophobic hollow fibers and found that it was a more promising technology than conventional scrubbers used in desulfurization. Park et al. [10] studied the effects of operation parameters on $\mathrm{SO}_{2}$ removal by PVDF hollow fiber membranes and found that it is one of the most competitive alternatives in the future. There is still $\mathrm{SO}_{2}$ that exists in the flue gas after desulfurization tower. The influence of $\mathrm{SO}_{2}$ on $\mathrm{CO}_{2}$ capture gained more attention recently. Zhong [11] studied the effect 
of $\mathrm{SO}_{2}$ concentration on MEA, MEA/MDEA, MEDA/PZ, and DEA/AMP. The tolerance of $\mathrm{SO}_{2}$ was found to be as follows: MEA > DEA/AMP > MEDA/PZ > MEA/MDEA. Uyanga and Idem [12] studied the degradation of MEA caused by $\mathrm{SO}_{2}$ in a semibatch reactor. The results show that $\mathrm{SO}_{2}$ accelerates the rate of MEA degradation and established a dynamic model. Supap et al. [13] studied the kinetics of $\mathrm{SO}^{2-}$ and $\mathrm{O}^{2-}$ induced degradation of aqueous MEA during $\mathrm{CO}_{2}$ capture. The results show that an increase in temperature and concentration of MEA, $\mathrm{O}_{2}$, and $\mathrm{SO}_{2}$ causes a higher degradation rate of MEA. Gao et al. [14] studied the effect of $\mathrm{SO}_{2}$ on the $\mathrm{CO}_{2}$ capture process in a pilot plant. The results show that $\mathrm{SO}_{2}$ causes amine oxidative degradation, which is beneficial to remove $\mathrm{SO}_{2}$ induced heat stable salts using appropriate methods. Bonenfant et al. [15] studied the absorption of $\mathrm{CO}_{2}$ and $\mathrm{SO}_{2}$ mixtures with the absorbent of aqueous 2-(2-aminoethylamino)ethanol (AEE) solution and its blends with N-methyldiethanolamine (MDEA) and triethanolamine (TEA) to estimate the influence of $\mathrm{SO}_{2}$. The results show that $\mathrm{SO}_{2}$ decreases the $\mathrm{CO}_{2}$ absorption rate. The addition of 5 and $10 \mathrm{wt} . \%$ of MDEA and TEA does not influence the $\mathrm{CO}_{2}$ absorption rate in AEE. TEA decreases the absorption capacity of AEE. Yang et al. [16] studied the influence of $\mathrm{SO}_{2}$ on the $\mathrm{CO}_{2}$ capture in an absorptiondesorption experimental setup using MEA as the absorbent. The results show that there were sharp decreases in $\mathrm{CO}_{2}$ removal efficiency and mass transfer rate of $\mathrm{CO}_{2}$ after the initial several days of operation; more progress is needed in high-efficiency and stable absorbents.

According to the present research situation, $\mathrm{SO}_{2}$ causes the degradation of alcohol amine absorbent, resulting in the decrease of $\mathrm{CO}_{2}$ removal efficiency. The influence of $\mathrm{SO}_{2}$ on $\mathrm{CO}_{2}$ absorption by alcohol amine absorbent deserves attention. It is necessary to research the optimization of $\mathrm{CO}_{2}$ absorption characteristic under the influence of $\mathrm{SO}_{2}$. Research on appropriate absorbent and parameter range which can inhibit the influence of $\mathrm{SO}_{2}$ is needed. MEA, MDEA, DEA, and other amine solutions [11-16] are selected as absorbent of $\mathrm{CO}_{2}$ capture by many researchers. The disadvantage of MEA is the high energy consumption in the $\mathrm{CO}_{2}$ desorption. The tolerance ability to $\mathrm{SO}_{2}$ of MEA is better than that of MDEA [11]. Studies on EDA as an absorbent used in $\mathrm{CO}_{2}$ capture are relatively fewer. In the study of Shunxiang [18], the performance of the absorbents used in $\mathrm{CO}_{2}$ absorption is as follows: $\mathrm{PZ}>\mathrm{EDA}>\mathrm{MEA}>$ DEA. Considering that $\mathrm{CO}_{2}$ removal efficiency of EDA is higher than of MEA, the tolerance ability to $\mathrm{SO}_{2}$ of MEA is high and the activation ability of $\mathrm{PZ}$ is good, and EDA, EDA + MEA, and EDA + MEA + PZ are selected as absorbents of $\mathrm{CO}_{2}$ capture in this paper. This paper researches the performance of these absorbents under the influence of $\mathrm{SO}_{2}$ in order to study the appropriate absorbent composition ratio and specific operating parameters to optimize $\mathrm{CO}_{2}$ absorption under the influence of $\mathrm{SO}_{2}$. The results of this study are an important reference for the industrial application of $\mathrm{CO}_{2}$ absorption by hollow fiber membrane contactor.

\section{Materials and Methods}

2.1. Reaction Mechanism. $\mathrm{SO}_{2}$ diffuses from gas phase to gas-liquid interface firstly and then diffuses from gas-liquid interface to liquid phase and dissolves in liquid. The reaction between $\mathrm{SO}_{2}$ and amine solution can be assumed as a combination of the physical dissolution of $\mathrm{SO}_{2}$ in water and the chemical absorption of amine solution. $\mathrm{SO}_{2}$ in water generates $\mathrm{SO}_{3}{ }^{2-}$ firstly $[11,19]$ :

$$
\begin{aligned}
\mathrm{SO}_{2}+\mathrm{H}_{2} \mathrm{O} & \longleftrightarrow \mathrm{H}^{+}+\mathrm{HSO}_{3}{ }^{-} \\
\mathrm{HSO}_{3}{ }^{-} & \longleftrightarrow \mathrm{H}^{+}+\mathrm{SO}_{3}{ }^{2-}
\end{aligned}
$$

The solubility of $\mathrm{SO}_{2}$ increased by the addition of amine solution, and the amine reacted with the hydrogen ion from the water and formed a compound of strong heat stability:

$$
\begin{aligned}
& \mathrm{RR}^{\prime} \mathrm{NH}+\mathrm{SO}_{2}+\mathrm{H}_{2} \mathrm{O} \longleftrightarrow \mathrm{RR}^{\prime} \mathrm{NH}_{2}{ }^{+}+\mathrm{HSO}_{3}{ }^{-} \\
& \text {With oxygen: } 2 \mathrm{HSO}_{3}{ }^{-}+\mathrm{O}_{2}=2 \mathrm{HSO}_{4}{ }^{-}
\end{aligned}
$$

The compound generated in formula (3) is stable and cannot be regenerated by heating, which results in degradation and depletion of the amine solution. In addition to this, it will cause solution foaming and decrease $\mathrm{CO}_{2}$ removal efficiency in the system in the long run.

For MEA, the reaction between $\mathrm{CO}_{2}$ and MEA is as follows [20-22]:

$$
\mathrm{CO}_{2}+2 \mathrm{RNH}_{2} \longrightarrow \mathrm{RNH}^{+} \mathrm{CO}_{2}{ }^{-}+\mathrm{RNH}_{3}{ }^{+}
$$

The reaction between $\mathrm{SO}_{2}$ and MEA is as follows [19]:

$$
\mathrm{SO}_{2}+2 \mathrm{RNH}_{2}+\mathrm{H}_{2} \mathrm{O} \longrightarrow 2 \mathrm{RNH}_{3}^{+}+\mathrm{SO}_{3}{ }^{2-}
$$

where $\mathrm{R}$ is $\mathrm{HOCH}_{2} \mathrm{CH}_{2}$.

2.2. Materials. The solutions of EDA (ethylenediamine), $\mathrm{EDA}+\mathrm{MEA}$ (monoethanolamine), and $\mathrm{EDA}+\mathrm{MEA}+\mathrm{PZ}$ (piperazine) are selected as absorbents for $\mathrm{CO}_{2}$ absorption in this experiment. The concentration of absorbent is $500 \mathrm{~mol} / \mathrm{m}^{3}$, and the mole ratio of the component in hybrid absorbent is $\mathrm{EDA}: \mathrm{MEA}=0.6: 0.4$ and $\mathrm{EDA}: \mathrm{MEA}: \mathrm{PZ}=$ $0.4: 0.4: 0.2$.

The pp (polypropylene) hollow fiber membrane contactor of KH-MF-4040N-PP is produced by Hangzhou Kaihong Membrane Technology Co., Ltd., and the specification and parameters are shown in Table 1. The membrane is designed by internal pressure and stretch forming. The inlet and outlet of the gas and liquid are arranged on the side and the end, respectively. The maximum pressure designed is $0.3 \mathrm{MPa}$, applicable to the $\mathrm{pH}$ of $1 \sim 14$, at $15 \sim 40^{\circ} \mathrm{C}$.

2.3. Experimental Procedures. The system is shown in Figure 1. The flue gas is simulated by mixed gas of $\mathrm{CO}_{2}, \mathrm{SO}_{2}$, and $\mathrm{N}_{2}$. The flue gas is introduced into fiber membrane contactor from compressed gas cylinders. The absorbent is introduced into the contactor by a pump. The gas flows in the tube side and the absorbent flows in the shell side. There are regulating valves at the outlet of the simulative flue gas 


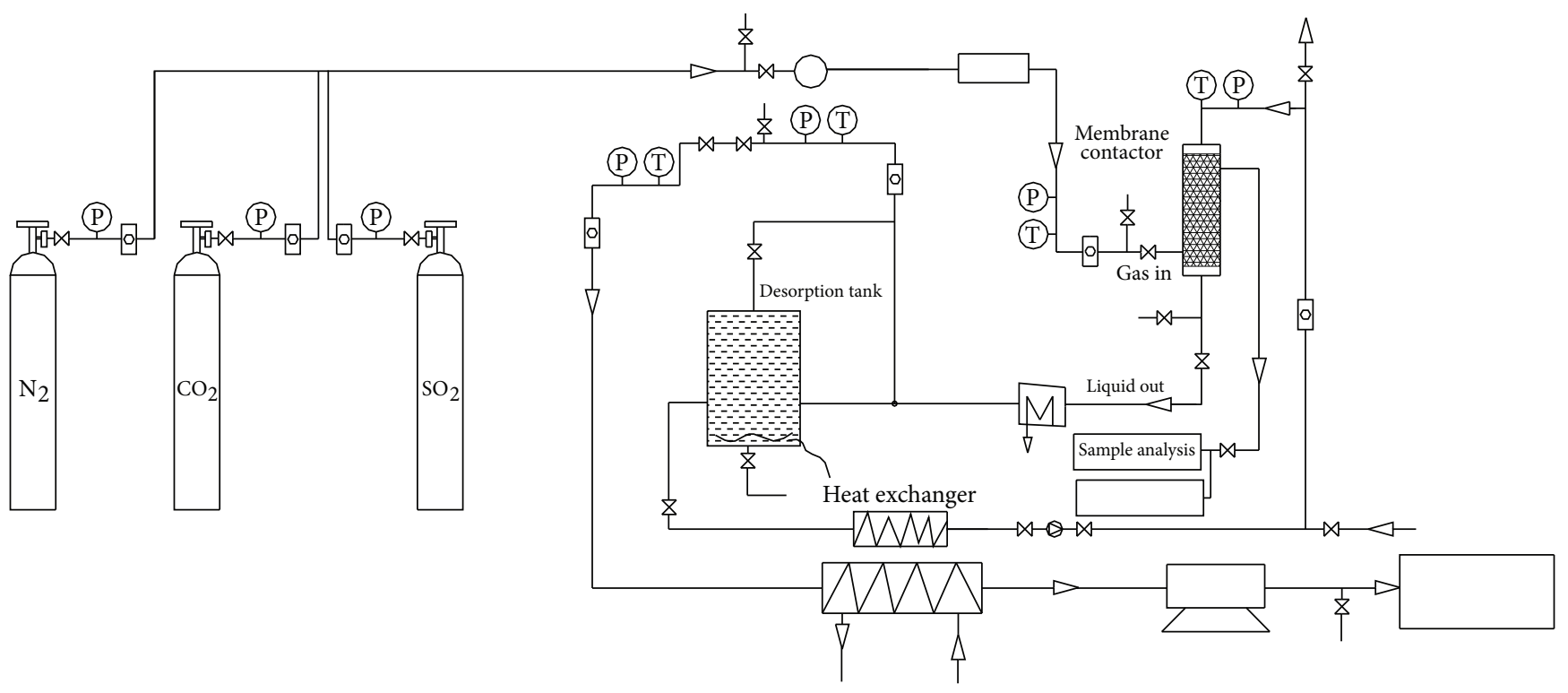

FIGURE 1: Flow chart of the experiment using the flue gas.

TABLE 1: Specifications and parameters of PP hollow fiber membrane contactor.

\begin{tabular}{lccc}
\hline Physical & Unit & Value & Parameter \\
\hline Liquid flux & $\mathrm{L} / \mathrm{h}$ & $800-1000$ & $U$ \\
Outer diameter of module & $\mathrm{mm}$ & 94 & $D_{\text {out }}$ \\
Inner diameter of module & $\mathrm{mm}$ & 90 & $D_{\text {in }}$ \\
Module length & $\mathrm{mm}$ & 1125 & $L_{m}$ \\
Fiber length & $\mathrm{mm}$ & 920 & $L$ \\
Membrane pore diameter & $\mu \mathrm{m}$ & $0.1-0.2$ & $d_{p}$ \\
Inner diameter of fiber & $\mathrm{mm}$ & 0.3 & $d_{\text {in }}$ \\
Outer diameter of fiber & $\mathrm{mm}$ & 0.4 & $d_{\text {out }}$ \\
Module area & $\mathrm{m}$ & $8 \sim 12$ & $S$ \\
Number of fibers & & 7000 & $n$ \\
Tortuosity factor & & 2 & $\tau$ \\
Fiber porosity & $\%$ & 45 & $\varepsilon$ \\
Packing density & $\%$ & 13.8 & $(1-\Phi)$ \\
\hline
\end{tabular}

and absorbent pump which can control the flow rate of gas and absorbent. The absorbent reacts with $\mathrm{CO}_{2}$ and becomes a rich liquid and is then introduced into the absorbent tank by a pump. The desorption tank desorbs $\mathrm{CO}_{2}$ by heating the rich liquid. This is one cycle of absorption and desorption. The desorption tank is designed by electric heating. There are sample portions to analyze the gas component by a gas analyzer (ECOM-J2KN, German RBR Company) and gas chromatograph (GC7900, Shanghai Tianmei Scientific Instruments Co., Ltd.). Values are obtained when the reaction is stable for $5 \mathrm{~min}$, and then an average value of three times is obtained, each time interval of $30 \mathrm{~s}$.

The experimental conditions and parameters are shown in Table 2. Gas flow rate is $4 \mathrm{~m}^{3} / \mathrm{h}$, and absorbent flow rate is $0.7 \mathrm{~m}^{3} / \mathrm{h}$. Volume fraction of $\mathrm{CO}_{2}$ in gas is $14 \mathrm{vol} . \%$.
TABle 2: Parameters of operating conditions.

\begin{tabular}{lccc}
\hline Parameter & Unit & Physical & Value \\
\hline$T_{g}$ & $\mathrm{~K}$ & Gas temperature & 288 \\
$T_{l}$ & $\mathrm{~K}$ & Absorbent temperature & 288 \\
$U_{g}$ & $\mathrm{~m}^{3} / \mathrm{h}$ & Gas flow rate & 4 \\
$U_{l}$ & $\mathrm{~m}^{3} / \mathrm{h}$ & Absorbent flow rate & 0.7 \\
$C$ & $\mathrm{~mol} / \mathrm{m}^{3}$ & Absorbent concentration & 500 \\
$\varphi_{\mathrm{CO}_{2}}$ & vol.\% & Volume fraction of $\mathrm{CO}_{2}$ in gas & 14 \\
$P$ & $\mathrm{MP}$ & Operating pressure & 0.1 \\
\hline
\end{tabular}

\section{Results and Discussion}

The $\mathrm{CO}_{2}$ removal efficiency is the parameter that reflects the $\mathrm{CO}_{2}$ removal performance; it can be calculated by [23]

$$
\eta=\frac{Q_{\text {in }} \times \varphi_{\text {in }}-Q_{\text {out }} \times \varphi_{\text {out }}}{Q_{\text {in }} \times \varphi_{\text {in }}} \times 100,
$$

where $\eta$ is the $\mathrm{CO}_{2}$ removal efficiency, $Q_{\text {in }}$ is the gas flow rate of inlet, $Q_{\text {out }}$ is the gas flow rate of outlet, and $\varphi_{\text {in }}$ and $\varphi_{\text {out }}$ are the volume fraction of $\mathrm{CO}_{2}$ at inlet and outlet, respectively.

The mass transfer rate reflects the performance of mass transfer. It can be calculated by [23]

$$
J_{\mathrm{CO}_{2}}=\frac{\left(Q_{\text {in }} \times \varphi_{\text {in }}-Q_{\text {out }} \times \varphi_{\text {out }}\right) \times 273.15 \times 1000}{22.4 \times T_{g} \times S},
$$

where $J_{\mathrm{CO}_{2}}$ is the mass transfer rate, $T_{g}$ is gas temperature, and $S$ is the total area of the membrane.

3.1. Influence of $\mathrm{SO}_{2}$ Concentration on $\mathrm{CO}_{2}$ Absorption. In order to emphasize the influence of $\mathrm{SO}_{2}$ concentration, the concentration of $\mathrm{SO}_{2}$ is amplified from $500 \mathrm{ppm}$ to $2000 \mathrm{ppm}$ in this research. The influences of $\mathrm{SO}_{2}$ concentration on $\mathrm{CO}_{2}$ 


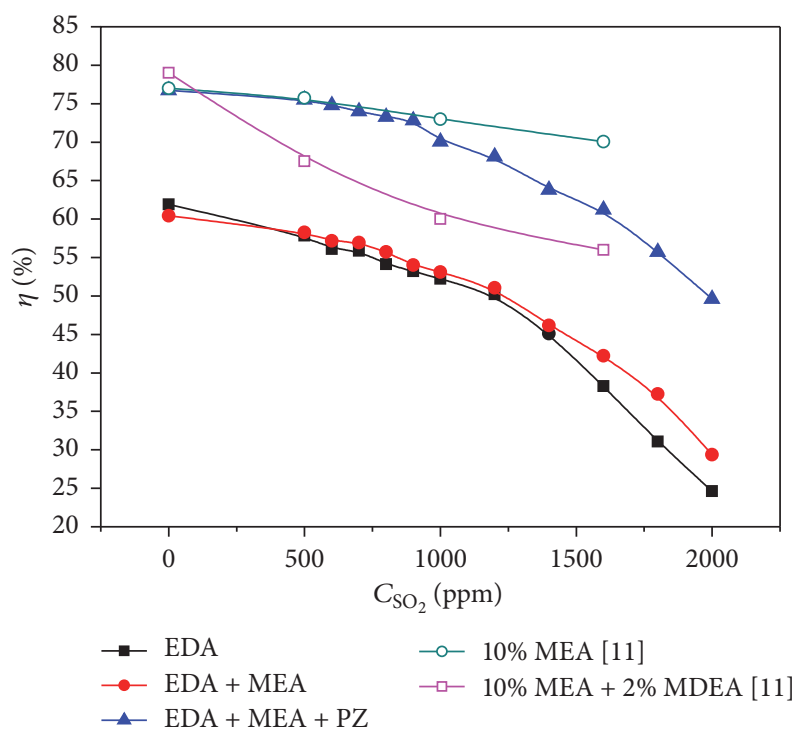

Figure 2: Influence of $\mathrm{SO}_{2}$ concentration on the $\mathrm{CO}_{2}$ removal efficiency $\left(U_{g}=4 \mathrm{~m}^{3} / \mathrm{h}, U_{l}=0.7 \mathrm{~m}^{3} / \mathrm{h}\right.$, and $\left.T=288 \mathrm{~K}\right)$.

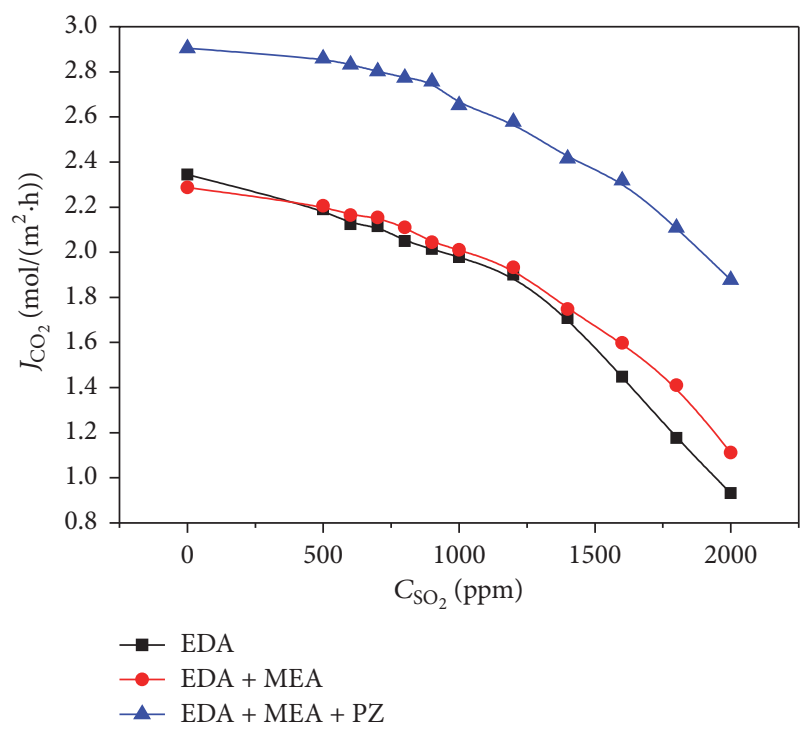

FIGURE 3: Influence of $\mathrm{SO}_{2}$ concentration on the $\mathrm{CO}_{2}$ mass transfer rate $\left(U_{g}=4 \mathrm{~m}^{3} / \mathrm{h}, U_{l}=0.7 \mathrm{~m}^{3} / \mathrm{h}\right.$, and $\left.T=288 \mathrm{~K}\right)$.

removal efficiency and mass transfer rate are shown in Figures 2 and 3. The $\mathrm{CO}_{2}$ removal efficiency and mass transfer rate of the three absorbents decrease with the increasing of $\mathrm{SO}_{2}$ concentration. The solubility of $\mathrm{SO}_{2}$ is much higher than of $\mathrm{CO}_{2}$. The $\mathrm{pH}$ value of $\mathrm{SO}_{2}$ aqueous solution is smaller than the $\mathrm{pH}$ value of $\mathrm{CO}_{2}$ equilibrium solution. The reaction between $\mathrm{SO}_{2}$ and amine absorbent can be considered as instantaneous [11]. The reaction rates and opportunities for $\mathrm{SO}_{2}$ and absorbent are much higher than those of $\mathrm{CO}_{2}$ and absorbent, which leads to the decrease of $\mathrm{CO}_{2}$ removal efficiency.

The $\mathrm{CO}_{2}$ removal efficiency of three absorbents decreased suddenly after 1000 ppm SO$S_{2}$. The effective components keep constant when the absorbent concentration is fixed. When $\mathrm{SO}_{2}$ concentration increased to a certain value, the effective components of absorbent are consumed largely by $\mathrm{SO}_{2}$, which leads to the sudden decrease of $\mathrm{CO}_{2}$ removal efficiency. The $\mathrm{CO}_{2}$ removal efficiency of EDA decreases by $4.05 \%$ with $500 \mathrm{ppm} \mathrm{SO}$ and decreases by $37.3 \%$ with 2000 ppm $\mathrm{SO}_{2}$. It can be considered that the influence of $\mathrm{SO}_{2}$ on $\mathrm{CO}_{2}$ removal efficiency with EDA is not significant when the $\mathrm{SO}_{2}$ concentration is under $500 \mathrm{ppm}$. Because of the low concentration of $\mathrm{SO}_{2}$, even with the faster reaction rate of $\mathrm{SO}_{2}$, there is still a chance for $\mathrm{CO}_{2}$ to react with the absorbent. The concentration gradient of the gas and the liquid vapor interface increases with increasing $\mathrm{SO}_{2}$ concentration, which improves the mass transfer dynamics. This is favorable for $\mathrm{SO}_{2}$ molecules to diffuse to the surface and the interior of the absorption solution and speed up the reaction of $\mathrm{SO}_{2}$ with EDA. Therefore, the absorption of $\mathrm{CO}_{2}$ reduced greatly with the increasing of $\mathrm{SO}_{2}$ concentration. The influence of $\mathrm{SO}_{2}$ on $\mathrm{CO}_{2}$ removal efficiency is more significant with the increase of $\mathrm{SO}_{2}$ concentration. The $\mathrm{SO}_{2}$ concentration in the outlet of flue gas is always zero, which indicates that $\mathrm{SO}_{2}$ is absorbed by the absorbent completely, and the reaction rate of $\mathrm{SO}_{2}$ and the absorbent is significantly higher than that of $\mathrm{CO}_{2}$ and the absorbent.

The $\mathrm{CO}_{2}$ removal efficiency of EDA + MEA decreases by $2.1 \%$ with 500 ppm SO , the efficiency is $53.1 \%$ with $1000 \mathrm{ppm}$ $\mathrm{SO}_{2}$, and the efficiency decreases to $29.3 \%$ with $2000 \mathrm{ppm}$ $\mathrm{SO}_{2}$. Comparing the results of EDA + MEA (0.6:0.4) and EDA, the $\mathrm{CO}_{2}$ removal efficiency and mass transfer rate of EDA are higher than those of EDA + MEA without the addition of $\mathrm{SO}_{2}$. With the increasing of $\mathrm{SO}_{2}$ concentration, the $\mathrm{CO}_{2}$ removal efficiency and mass transfer rate of EDA + MEA (0.6:0.4) are higher than those of EDA. The $\mathrm{CO}_{2}$ absorption capacity of EDA is better than that of MEA [18]; therefore, the $\mathrm{CO}_{2}$ removal efficiency and mass transfer rate of EDA are higher than those of EDA + MEA (0.6:0.4) without the influence of $\mathrm{SO}_{2}$. The active ingredient increases after the addition of MEA, which promotes the tolerance ability of the absorbent to $\mathrm{SO}_{2}$. The $\mathrm{CO}_{2}$ removal efficiency and mass transfer rate reduction of EDA + MEA (0.6:0.4) are smaller than those of EDA; therefore, the tolerance ability of EDA + MEA (0.6:0.4) to $\mathrm{SO}_{2}$ is better than that of EDA.

Zhong [11] researched the influence of $\mathrm{SO}_{2}$ concentration on $\mathrm{CO}_{2}$ absorption with the absorbent of $10 \%$ MEA and $10 \%$ MEA + $2 \%$ MDEA (liquid flow rate $18 \mathrm{~L} / \mathrm{h}$, temperature $40^{\circ} \mathrm{C}$; flue gas flow rate $1800 \mathrm{~L} / \mathrm{h}$, temperature $15^{\circ} \mathrm{C} ; \mathrm{SO}_{2}$ concentration is $500-1500 \mathrm{ppm}$ ). The results are shown in Figure 2. The results indicate that the $\mathrm{CO}_{2}$ removal efficiency decreases with the increase of $\mathrm{SO}_{2}$ concentration, and the influence of $\mathrm{SO}_{2}$ is not significant till the $\mathrm{SO}_{2}$ concentration becomes greater than $500 \mathrm{ppm}$, which agrees well with the results in this paper. The $\mathrm{CO}_{2}$ removal efficiency of $10 \% \mathrm{MEA}+$ $2 \%$ MDEA is higher than that of $10 \%$ MEA when $\mathrm{SO}_{2}$ concentration is under $117 \mathrm{ppm}$, and the decrease extent of $\mathrm{CO}_{2}$ removal efficiency in $10 \% \mathrm{MEA}+2 \%$ MDEA is more than that in $10 \% \mathrm{MEA}$ with the increase of $\mathrm{SO}_{2}$ concentration. The $\mathrm{CO}_{2}$ removal efficiency of $10 \%$ MEA is higher than that of $10 \% \mathrm{MEA}+2 \% \mathrm{MDEA}$ with $200 \mathrm{ppm} \mathrm{SO}$. This indicates that the reaction between $10 \% \mathrm{MEA}+2 \% \mathrm{MDEA}$ and $\mathrm{SO}_{2}$ 


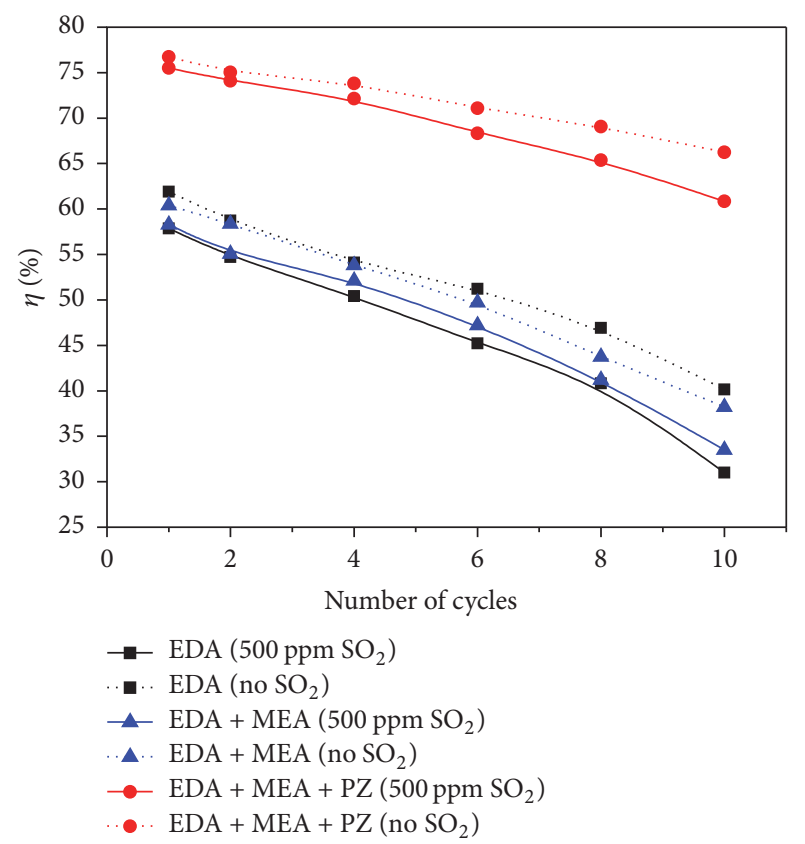

FIGURE 4: Influence of cycle absorption and desorption on the $\mathrm{CO}_{2}$ removal efficiency $\left(U_{g}=4 \mathrm{~m}^{3} / \mathrm{h}, U_{l}=0.7 \mathrm{~m}^{3} / \mathrm{h}\right.$, and $\left.T=288 \mathrm{~K}\right)$.

is more rapid and intense, so the decrease extent of $\mathrm{CO}_{2}$ removal efficiency with the absorbent of $10 \% \mathrm{MEA}+2 \%$ MDEA is more significant than of $10 \%$ MEA. Because of the poor absorptive capacity and slow absorption rate of MDEA, MDEA is not suitable for $\mathrm{CO}_{2}$ absorption with the influence of $\mathrm{SO}_{2}$. The tolerance ability of $10 \% \mathrm{MEA}+2 \% \mathrm{MDEA}$ to $\mathrm{SO}_{2}$ is lower than that of $10 \%$ MEA.

Comparing the results of EDA and 10\% MEA, the $\mathrm{CO}_{2}$ removal efficiency of $10 \% \mathrm{MEA}$ is higher than of EDA without $\mathrm{SO}_{2}$, and the decrease extent is smaller than EDA with the increase of $\mathrm{SO}_{2}$ concentration. So, the tolerance ability to $\mathrm{SO}_{2}$ of $10 \% \mathrm{MEA}$ is greater than $500 \mathrm{~mol} / \mathrm{m}^{3} \mathrm{EDA}$. After adding of MEA, the $\mathrm{CO}_{2}$ removal efficiency of EDA + MEA $(0.6: 0.4)$ is higher than of EDA with the increase of $\mathrm{SO}_{2}$ concentration. So, the hybrid absorbent of EDA + MEA $(0.6: 0.4)$ is appropriate for removal of $\mathrm{CO}_{2}$ in the flue gas containing $\mathrm{SO}_{2}$.

The absorbent of EDA + MEA + PZ is the most efficient in the three absorbents. The $\mathrm{CO}_{2}$ removal efficiency of EDA + $\mathrm{MEA}+\mathrm{PZ}$ decreases by $1.2 \%$ with 500 ppm $\mathrm{SO}_{2}$, decreases by $3.4 \%$ with $800 \mathrm{ppm} \mathrm{SO}_{2}$, and decreases by $27.1 \%$ with $2000 \mathrm{ppm} \mathrm{SO}_{2}$. The $\mathrm{CO}_{2}$ removal efficiency reduction of EDA $+\mathrm{MEA}+\mathrm{PZ}$ is not significant until $1000 \mathrm{ppm} \mathrm{SO}_{2}$. Because of the activity of $\mathrm{PZ}$, the influence of $\mathrm{SO}_{2}$ on $\mathrm{CO}_{2}$ absorption with $\mathrm{EDA}+\mathrm{MEA}+\mathrm{PZ}$ is not significant under the condition of low $\mathrm{SO}_{2}$ concentration in a short time. And the tolerance ability of EDA + MEA + PZ to $\mathrm{SO}_{2}$ is greater than that of $\mathrm{EDA}$ and $\mathrm{EDA}+\mathrm{MEA}$. The influence of $\mathrm{SO}_{2}$ is getting more significant when the $\mathrm{PZ}$ active effect is gradually consumed. Therefore, the $\mathrm{CO}_{2}$ removal efficiency decreases significantly with $2000 \mathrm{ppm} \mathrm{SO}_{2}$.

The results of the three absorbents indicate that the influence of $\mathrm{SO}_{2}$ on $\mathrm{CO}_{2}$ is not significant with low $\mathrm{SO}_{2}$

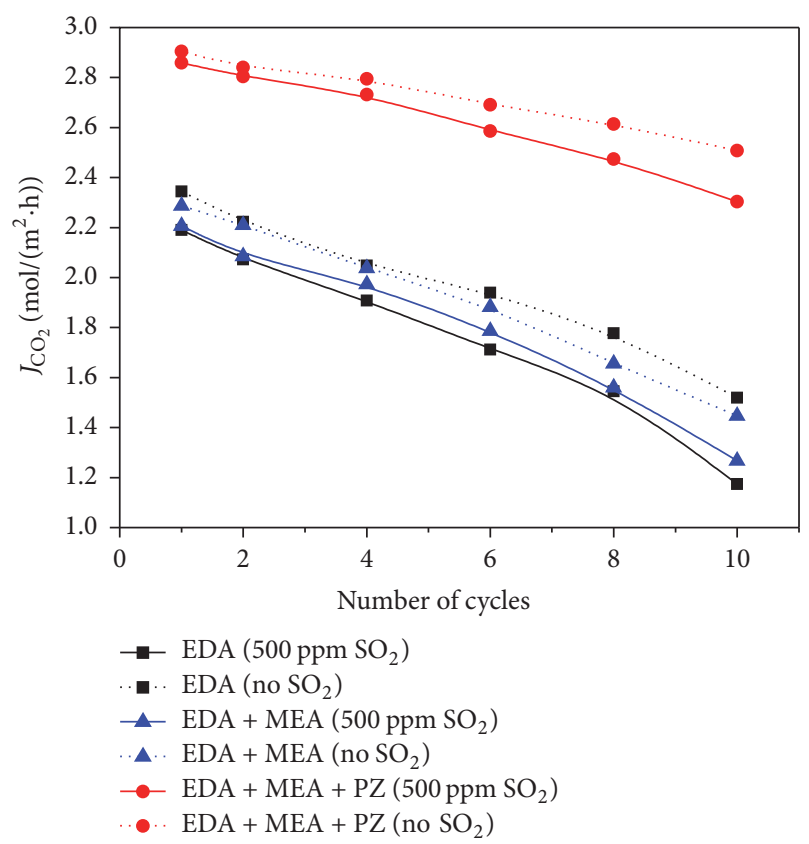

FIGURE 5: Influence of cycle absorption and desorption on the $\mathrm{CO}_{2}$ mass transfer rate $\left(U_{g}=4 \mathrm{~m}^{3} / \mathrm{h}, U_{l}=0.7 \mathrm{~m}^{3} / \mathrm{h}\right.$, and $\left.T=288 \mathrm{~K}\right)$.

concentration in the short run performance; the hybrid absorbent with high absorptive capacity component and high tolerance ability to $\mathrm{SO}_{2}$ can inhibit the influence of $\mathrm{SO}_{2}$ on $\mathrm{CO}_{2}$ absorption effectively.

3.2. Cycle Absorption and Desorption Characteristic of Absorbent. According to the previous research, the influence of $\mathrm{SO}_{2}$ on $\mathrm{CO}_{2}$ absorption is not significant in the low concentration of $\mathrm{SO}_{2}$. The absorption experiment is conducted in a short time, and the cycle absorption and desorption of the absorbent are not considered. It is necessary to study the cycle absorption and desorption of the absorbent. Based on the influence of $\mathrm{SO}_{2}$ concentration on $\mathrm{CO}_{2}$ removal efficiency, the influence is not significant when the $\mathrm{SO}_{2}$ concentration is below 500 ppm of the three absorbents. In order to study the influence of $\mathrm{SO}_{2}$ on $\mathrm{CO}_{2}$ absorption in low $\mathrm{SO}_{2}$ concentration, the $\mathrm{SO}_{2}$ concentration of $500 \mathrm{ppm}$ is selected in this experiment.

The results are shown in Figures 4 and 5. The absorbent from absorption to desorption is one cycle. The $\mathrm{CO}_{2}$ removal efficiency and mass transfer rate decrease with the increase of cycle number. The $\mathrm{CO}_{2}$ removal efficiency of EDA decreases by $26.85 \%$ with $\mathrm{SO}_{2}$ and decreases by $21.8 \%$ without $\mathrm{SO}_{2}$; the $\mathrm{CO}_{2}$ removal efficiency of $\mathrm{EDA}+\mathrm{MEA}$ decreases by $24.7 \%$ with $\mathrm{SO}_{2}$ and decreases by $22.1 \%$ without $\mathrm{SO}_{2}$; the $\mathrm{CO}_{2}$ removal efficiency of EDA + MEA + PZ decreases by $14.6 \%$ with the influence of $\mathrm{SO}_{2}$.

Desorption of the absorbent by heating the rich liquid results in absorbent degradation. $\mathrm{SO}_{2}$ reacts with the absorbent and generates stable salts, which cannot be regenerated by heating. The existence of $\mathrm{SO}_{2}$ accelerates the degradation of most amine solutions. Strazisar et al. [24] studied the effect of $\mathrm{SO}_{2}$ on the degradation of MEA. The 


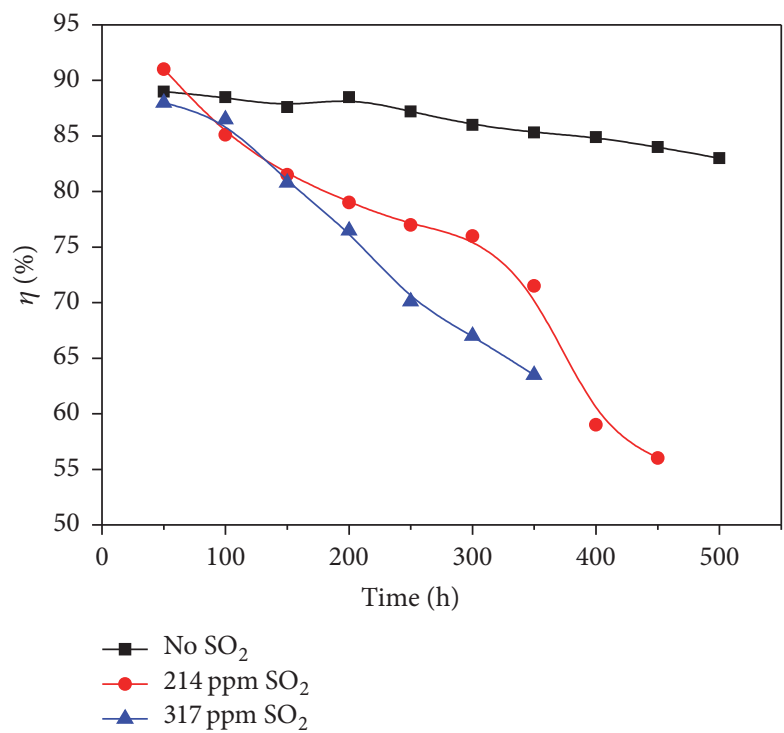

FIGURE 6: The influence of circulating time on the $\mathrm{CO}_{2}$ removal efficiency [17] $\left(U_{g}=86 \mathrm{Nm}^{3} / \mathrm{h}, U_{l}=0.6 \mathrm{~m}^{3} / \mathrm{h}\right.$, and $\left.T=319 \mathrm{~K}\right)$.

results show that $\mathrm{SO}_{2}$ accelerates the degradation rate of MEA, which is significant in higher concentration of $\mathrm{SO}_{2}$. Therefore, the $\mathrm{CO}_{2}$ removal efficiency and mass transfer rate decrease significantly with the increasing cycle of absorption and desorption.

Gao et al. [17] studied the influence of $\mathrm{SO}_{2}$ on the absorption character of absorbent in the following campaign: no $\mathrm{SO}_{2}, 214 \mathrm{ppm} \mathrm{SO}$, and $317 \mathrm{ppm} \mathrm{SO}$, respectively. The result is shown in Figure 6. The $\mathrm{CO}_{2}$ removal efficiency decreases gradually with increasing circulating time. And the decrease extent of $\mathrm{CO}_{2}$ removal efficiency increases with $\mathrm{SO}_{2}$ concentration. The absorbent degradation and heat stable salts formation are the main reasons for the significant influence of $\mathrm{SO}_{2}$. The trend of Figure 4 in this experiment agreed with the trend of Figure 6.

The study in this section indicated that there is a significant influence of $\mathrm{SO}_{2}$ on $\mathrm{CO}_{2}$ absorption even in low $\mathrm{SO}_{2}$ concentration in the long run performance. The order of tolerance ability to $\mathrm{SO}_{2}$ is EDA + MEA + PZ $(0.4: 0.4: 0.2)>$ $\mathrm{EDA}+\mathrm{MEA}(0.6: 0.4)>\mathrm{EDA}$. The $\mathrm{CO}_{2}$ removal efficiency of $\mathrm{EDA}+\mathrm{MEA}+\mathrm{PZ}(0.4: 0.4: 0.2)$ decreased to $60 \%$ after ten absorption and desorption cycles. Therefore, it is necessary to study the appropriate parameter range in the operation to inhibit the influence of $\mathrm{SO}_{2}$.

\subsection{The Influence of Absorbent Concentration on $\mathrm{CO}_{2}$ Absorp-} tion. The concentration of absorbent is one of the most important parameters of $\mathrm{CO}_{2}$ absorption in operation. The influence of absorbent concentration on $\mathrm{CO}_{2}$ removal efficiency is studied in this section for confirming the appropriate concentration of the absorbent which can inhibit the influence of $\mathrm{SO}_{2}$.

The $\mathrm{CO}_{2}$ removal efficiency of the three absorbents decreased suddenly after $1000 \mathrm{ppm} \mathrm{SO}_{2}$ in the study of influence of $\mathrm{SO}_{2}$ concentration. Therefore, the experiment is

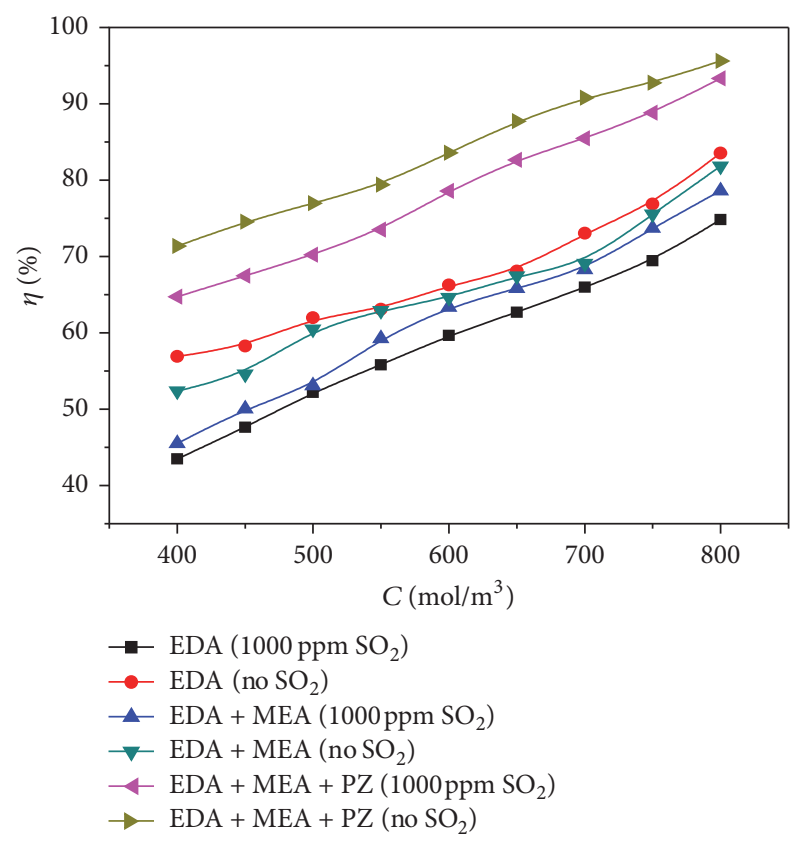

Figure 7: Influence of $\mathrm{SO}_{2}$ on the $\mathrm{CO}_{2}$ removal efficiency in different concentrations of absorbent $\left(U_{g}=4 \mathrm{~m}^{3} / \mathrm{h}, U_{l}=0.7 \mathrm{~m}^{3} / \mathrm{h}\right.$, and $T=288 \mathrm{~K})$.

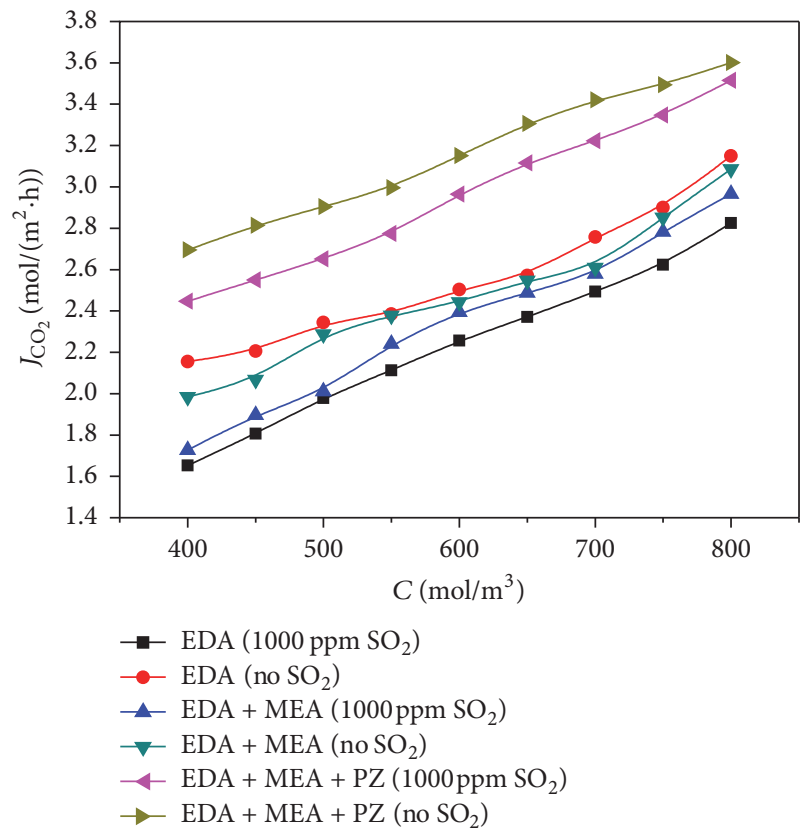

FIGURE 8: Influence of $\mathrm{SO}_{2}$ on the $\mathrm{CO}_{2}$ mass transfer rate in different concentrations of absorbent $\left(U_{g}=4 \mathrm{~m}^{3} / \mathrm{h}, U_{l}=0.7 \mathrm{~m}^{3} / \mathrm{h}\right.$, and $T=$ $288 \mathrm{~K})$.

conducted under the condition of $1000 \mathrm{ppm} \mathrm{SO}_{2}$. The concentration of the absorbent is from $400 \mathrm{~mol} / \mathrm{m}^{3}$ to $800 \mathrm{~mol} / \mathrm{m}^{3}$. The $\mathrm{CO}_{2}$ removal efficiency and mass transfer rate increase with the increasing absorbent concentration which is shown in Figures 7 and 8. Comparing the result of $1000 \mathrm{ppm} \mathrm{SO}_{2}$ with that of no $\mathrm{SO}_{2}$, the $\mathrm{CO}_{2}$ 
removal efficiency of $400 \mathrm{~mol} / \mathrm{m}^{3} \mathrm{EDA}, 600 \mathrm{~mol} / \mathrm{m}^{3} \mathrm{EDA}$, and $650 \mathrm{~mol} / \mathrm{m}^{3}$ EDA decreases by $13.27 \%, 6.5 \%$, and $5.3 \%$, respectively. The decreasing extent of $\mathrm{CO}_{2}$ removal efficiency and mass transfer rate of absorbent reduce with the increasing absorbent concentration.

A certain amount of absorbent is needed when the concentration of $\mathrm{SO}_{2}$ keeps constant in flue gas. There are more active ingredients in the absorbent to improve the $\mathrm{CO}_{2}$ absorption with the increase of absorbent concentration. Therefore, increasing absorbent concentration can inhibit the influence of $\mathrm{SO}_{2}$ on $\mathrm{CO}_{2}$ absorption. The cost and the energy consumption increase with the increasing absorbent concentration. Hence, there is an appropriate concentration of absorbent which can inhibit the influence of $\mathrm{SO}_{2}$ on $\mathrm{CO}_{2}$ absorption with low cost and low energy consumption. The $\mathrm{CO}_{2}$ removal efficiency of $800 \mathrm{~mol} / \mathrm{m}^{3} \mathrm{EDA}, 750 \mathrm{~mol} / \mathrm{m}^{3}$ $\mathrm{EDA}+\mathrm{MEA}$, and $650 \mathrm{~mol} / \mathrm{m}^{3} \mathrm{EDA}+\mathrm{MEA}+\mathrm{PZ}$ is $75 \%$, $74 \%$, and $83 \%$, respectively, with $1000 \mathrm{ppm} \mathrm{SO}_{2}$. Continuing to increase the absorbent concentration, the increment of $\mathrm{CO}_{2}$ removal efficiency will reduce because the absorbent viscosity and the mass transfer resistance increase with the increasing absorbent concentration. Furthermore, continuing to increase the absorbent concentration will increase investment and operating costs. Considering the above factors, under the condition of $1000 \mathrm{ppm} \mathrm{SO}_{2}$, the appropriate concentrations of EDA, EDA + MEA, and EDA + MEA + PZ are $800 \mathrm{~mol} / \mathrm{m}^{3}, 750 \mathrm{~mol} / \mathrm{m}^{3}$, and $650 \mathrm{~mol} / \mathrm{m}^{3}$, respectively.

3.4. Influence of the Liquid-Gas Flow Rate Ratio on $\mathrm{CO}_{2}$ Absorption. The flow rates of absorbent and gas are important parameters which can affect the $\mathrm{CO}_{2}$ absorption significantly. It is necessary to study the appropriate ratio of liquidgas flow rate for inhibiting the influence of $\mathrm{SO}_{2}$.

With the increasing ratio of liquid-gas flow rate under the condition of $1000 \mathrm{ppm} \mathrm{SO}$, the $\mathrm{CO}_{2}$ absorption characteristic of EDA, EDA + MEA, and EDA + MEA + PZ is shown in Figures 9 and 10. The $\mathrm{CO}_{2}$ removal efficiency and mass transfer rate rise with the increasing ratio of liquid-gas flow rate. With the addition of $\mathrm{SO}_{2}$, the $\mathrm{CO}_{2}$ removal efficiency of EDA decreases by $7.9 \%, 6.28 \%$, and $5.26 \%$, respectively, when the ratio of liquid-gas flow rate is $0.1,0.15$, and 0.25 individually. The $\mathrm{CO}_{2}$ removal efficiency difference between the case with $\mathrm{SO}_{2}$ and that without $\mathrm{SO}_{2}$ decreases with the increasing ratio of liquid-gas flow rate. The experimental results of EDA + MEA and EDA + MEA $+\mathrm{PZ}$ are similar to that of EDA. Therefore, the influence of $\mathrm{SO}_{2}$ on $\mathrm{CO}_{2}$ absorption decreases with the increasing ratio of liquid-gas flow rate. Lv et al. [25] studied the simultaneous removal of $\mathrm{CO}_{2}$ and $\mathrm{SO}_{2}$ in a polypropylene hollow fiber membrane contactor using MEA. The $\mathrm{CO}_{2}$ removal efficiency of MEA with $1600 \mathrm{ppm}$ increased with the liquid flow rate. The experimental result in this section of this paper agrees with the result of Lv et al.

With a certain concentration of $\mathrm{SO}_{2}$, the reaction of absorbent with $\mathrm{CO}_{2}$ increases gradually with the increasing ratio of liquid-gas flow rate. The mass transfer rate increases with the ratio of liquid-gas flow rate under a certain gas condition. Because of the increment of concentration gradients,

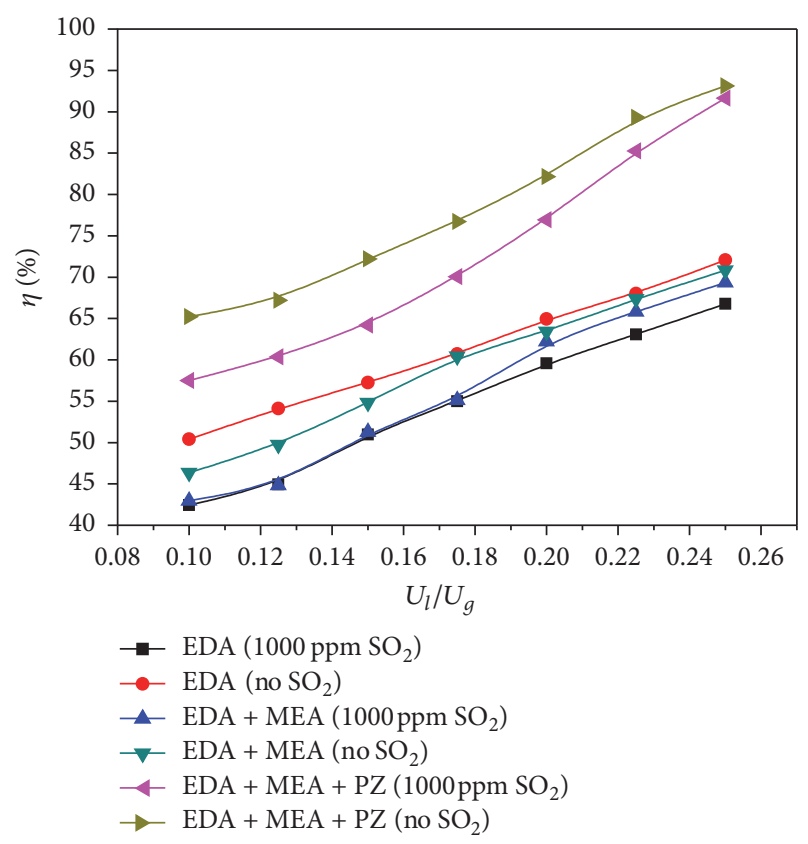

FIGURE 9: Influence of $\mathrm{SO}_{2}$ on the $\mathrm{CO}_{2}$ mass transfer rate in different liquid-gas flow rate ratios $(T=288 \mathrm{~K})$.

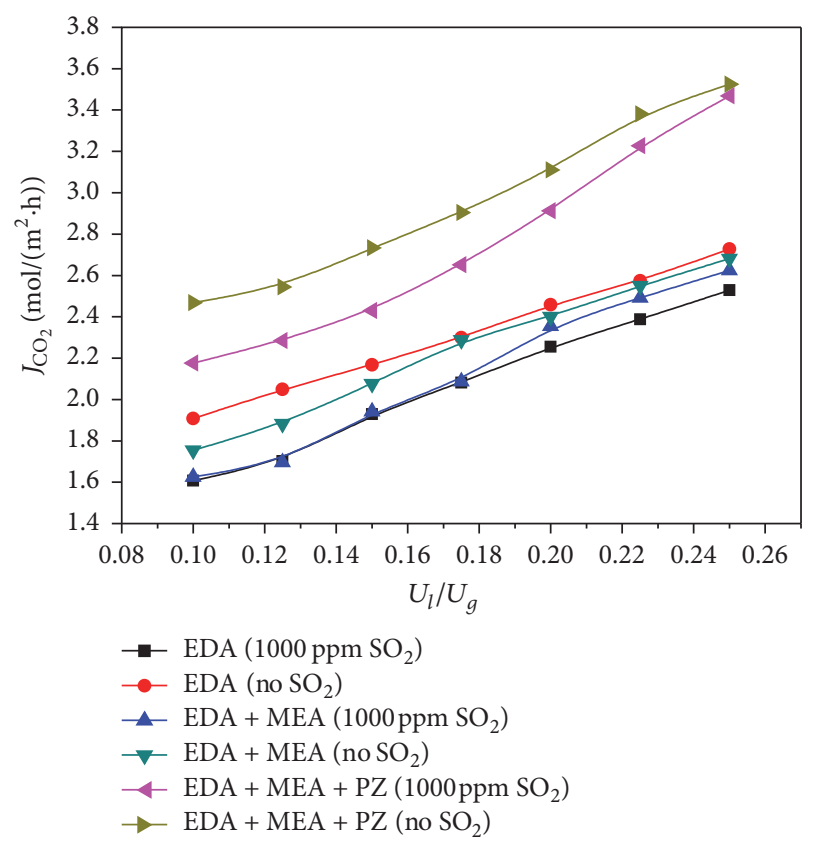

Figure 10: Influence of $\mathrm{SO}_{2}$ on the $\mathrm{CO}_{2}$ mass transfer rate in different liquid-gas flow rate ratios $(T=288 \mathrm{~K})$.

the mass transfer and the reaction of absorbent and $\mathrm{CO}_{2}$ are improved. The increase of absorbent flow rate accelerates the membrane wetting and wear, which result in a mass transfer resistance increase. Therefore, the increments of $\mathrm{CO}_{2}$ removal efficiency and mass transfer rate reduce with the increasing ratio of liquid-gas flow rate. Meanwhile, the consumption of absorbent and pump increases with the increasing liquidgas flow rate ratio, which raises the operation cost. In the 
liquid-gas flow rate ratio of $0.2-0.25$, the lowest $\mathrm{CO}_{2}$ removal efficiencies of EDA, EDA + MEA, and EDA + MEA + PZ are $60 \%, 63 \%$, and $77 \%$, respectively; the highest $\mathrm{CO}_{2}$ removal efficiencies of EDA, EDA + MEA, and EDA + MEA + PZ are $67 \%, 70 \%$, and $92 \%$, respectively. In order to inhibit the influence of $\mathrm{SO}_{2}$ on $\mathrm{CO}_{2}$ absorption and maintain high $\mathrm{CO}_{2}$ removal efficiency and low operating cost, under the condition of $1000 \mathrm{ppm} \mathrm{SO}_{2}$, the appropriate liquid-gas flow rate ratio of EDA, $\mathrm{EDA}+\mathrm{MEA}$, and $\mathrm{EDA}+\mathrm{MEA}+\mathrm{PZ}$ is from 0.2 to 0.25 .

\section{Conclusions}

There is a significant influence of $\mathrm{SO}_{2}$ on $\mathrm{CO}_{2}$ absorption in the long run performance, which affects the industrial application prospects of this technology. It is necessary to study the $\mathrm{SO}_{2}$ influence characteristic on $\mathrm{CO}_{2}$ absorption and the measure to optimize the $\mathrm{CO}_{2}$ absorption under the influence of $\mathrm{SO}_{2}$.

This paper studied the optimization of $\mathrm{CO}_{2}$ absorption characteristic under the influence of $\mathrm{SO}_{2}$ with the absorbent of EDA, EDA + MEA, and EDA + MEA + PZ by hollow fiber membrane contactor. The $\mathrm{SO}_{2}$ concentration, cycle absorption and desorption characteristic of absorbent, absorbent concentration, and ratio of liquid-gas flow rate are analyzed to evaluate the influence of $\mathrm{SO}_{2}$ on $\mathrm{CO}_{2}$ absorption characteristic. The reaction rate and absorption performance of $\mathrm{SO}_{2}$ with amine solution are much greater than those of $\mathrm{CO}_{2}$ with amine solution, resulting in decreases of $\mathrm{CO}_{2}$ removal efficiency and mass transfer rate in different extent with the absorbent of EDA, EDA + MEA, and EDA + MEA + PZ. The $\mathrm{CO}_{2}$ removal efficiency and mass transfer rate decrease with the increasing $\mathrm{SO}_{2}$ concentration and absorption and desorption cycle of absorbent.

This paper proposes appropriate absorbent composition ratio and operation parameters range which can inhibit the influence of $\mathrm{SO}_{2}$ on $\mathrm{CO}_{2}$ absorption and optimize the $\mathrm{CO}_{2}$ absorption under the influence of $\mathrm{SO}_{2}$. Depending on the results in this research, hybrid absorbent with activator agent, appropriate absorbent concentration, and ratio of liquid-gas flow rate can inhibit the influence of $\mathrm{SO}_{2}$ on $\mathrm{CO}_{2}$ absorption effectively. EDA + MEA + PZ (0.4:0.4:0.2) has the best tolerance ability to $\mathrm{SO}_{2}$ among the three absorbents. Under the condition of $1000 \mathrm{ppm} \mathrm{SO}_{2}$ in flue gas, the appropriate absorbent concentrations of EDA, EDA + MEA, and EDA + $\mathrm{MEA}+\mathrm{PZ}$ are $800 \mathrm{~mol} / \mathrm{m}^{3}, 750 \mathrm{~mol} / \mathrm{m}^{3}$, and $650 \mathrm{~mol} / \mathrm{m}^{3}$, respectively, and the appropriate ratio of liquid-gas flow rate is in the range from 0.2 to 0.25 .

\section{Nomenclature}

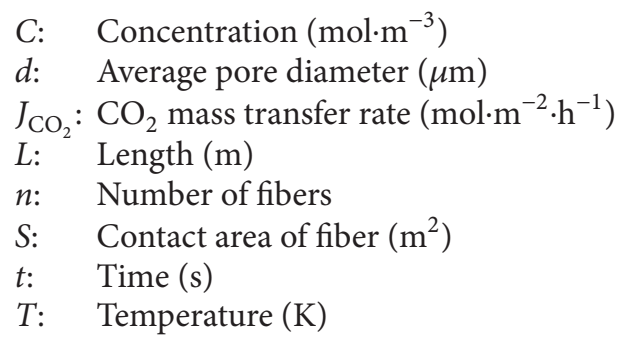

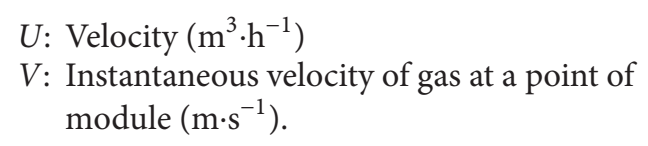

\section{Greek Letters}

$\begin{array}{ll}\eta: & \mathrm{CO}_{2} \text { removal efficiency (\%) } \\ \varepsilon: & \text { Porosity of fiber membrane (\%) } \\ \varphi: & \text { Volume fraction of } \mathrm{CO}_{2} \text { in gas (vol.\%) } \\ \tau: & \text { Tortuosity factor of fiber membrane } \\ (1-\Phi): & \text { Packing density of fiber membrane. }\end{array}$

Subscripts

g: Gas

$l$ : $\quad$ Liquid

in: Inlet

out: Outlet.

\section{Abbreviations}

EDA: Ethylenediamine

PZ: Piperazine

MEA: Monoethanol

PP: Polypropylene.

\section{Competing Interests}

The authors declare no competing interests regarding the publication of this paper.

\section{Acknowledgments}

This research is supported by the Science and Technology Project of Chongqing Municipal Education Commission (KJ1502503) and the Fundamental Research Funds for the Central Universities (no. CDJZR14145501).

\section{References}

[1] J. G. J. Olivier, G. Janssens-Maenhout, M. Muntean, and J. A. H. W. Peters, Trends in Global $\mathrm{CO}_{2}$ Emissions: 2014 Report, PBL Netherlands Environmental Assessment Agency, The Hague, The Netherlands, 2014.

[2] V. Y. Dindore, Gas Purification Using Membrane Gas Absorption Processes, University of Twente, 2003.

[3] H.-K. Lee, H.-D. Jo, W.-K. Choi, H.-H. Park, C.-W. Lim, and Y.T. Lee, "Absorption of $\mathrm{SO}_{2}$ in hollow fiber membrane contactors using various aqueous absorbents," Desalination, vol. 200, no. 13, pp. 604-605, 2006.

[4] R. Faiz and M. Al-Marzouqi, "Mathematical modeling for the simultaneous absorption of $\mathrm{CO}_{2}$ and $\mathrm{H}_{2} \mathrm{~S}$ using MEA in hollow fiber membrane contactors," Journal of Membrane Science, vol. 342, no. 1-2, pp. 269-278, 2009.

[5] W. Wammers, "A flexible process for acid gas removal from natural gas," in 73rdGPA Annu Groc Gas Process Handbook, vol. 75, no. 4, p. 105, 1996.

[6] P. Luis, A. Garea, and A. Irabien, "Zero solvent emission process for sulfur dioxide recovery using a membrane contactor and ionic liquids," Journal of Membrane Science, vol. 330, no. 1-2, pp. 80-89, 2009. 
[7] P. Luis, A. Garea, and A. Irabien, "Environmental and economic evaluation of $\mathrm{SO}_{2}$ recovery in a ceramic hollow fibre membrane contactor," Chemical Engineering and Processing: Process Intensification, vol. 52, pp. 151-154, 2012.

[8] U. Carbide, "New Cansolv technology from Union Carbide uses thermally regenerable organic amine salt to remove sulfur dioxide from flue gas," Chemical \& Engineering News, vol. 69, no. 46, p. 7, 1991.

[9] O. S. Ogundiran, S. Varanasi, and S. E. LeBlanc, "A novel gas desulfurization process using hollow fiber membranes," in Proceedings of the Air Pollution Control Association Annual Meeting, Cleveland, Ohio, USA, 1998.

[10] H. H. Park, B. R. Deshwal, I. W. Kim, and H. K. Lee, "Absorption of $\mathrm{SO}_{2}$ from flue gas using PVDF hollow fiber membranes in a gas-liquid contactor," Journal of Membrane Science, vol. 319, no. 1-2, pp. 29-37, 2008.

[11] W. Zhong, Study on $\mathrm{CO}_{2}$ Chemical Absorption Technology, ZheJiang University, 2008.

[12] I. J. Uyanga and R. O. Idem, "Studies of $\mathrm{SO}_{2}$ - and $\mathrm{O}_{2}$-induced degradation of aqueous MEA during $\mathrm{CO}_{2}$ capture from power plant flue gas streams," Industrial and Engineering Chemistry Research, vol. 46, no. 8, pp. 2558-2566, 2007.

[13] T. Supap, R. Idem, P. Tontiwachwuthikul, and C. Saiwan, "Kinetics of sulfur dioxide- and oxygen-induced degradation of aqueous monoethanolamine solution during $\mathrm{CO}_{2}$ absorption from power plant flue gas streams," International Journal of Greenhouse Gas Control, vol. 3, no. 2, pp. 133-142, 2009.

[14] J. Gao, S. Wang, S. Zhou, B. Zhao, C. Chen, and X. Xu, "Experimental study on the influence of $\mathrm{SO}_{2}$ on the $\mathrm{CO}_{2}$ capture process," Proceedings of The Chinese Society of Electrical Engineering, vol. 31, no. 5, pp. 52-57, 2011.

[15] D. Bonenfant, M. Mimeault, and R. Hausler, "Estimation of the $\mathrm{CO}_{2}$ absorption capacities in aqueous 2-(2-aminoethylamino)ethanol and its blends with MDEA and TEA in the presence of $\mathrm{SO}_{2}$," Industrial \& Engineering Chemistry Research, vol. 46, no. 26, pp. 8968-8971, 2007.

[16] J. Yang, X. Yu, J. Yan, S.-T. Tu, and E. Dahlquist, "Effects of $\mathrm{SO}_{2}$ on $\mathrm{CO}_{2}$ capture using a hollow fiber membrane contactor," Applied Energy, vol. 112, pp. 755-764, 2013.

[17] J. Gao, S. Wang, B. Zhao, G. Qi, and C. Chen, "Pilot-scale experimental study on the $\mathrm{CO}_{2}$ capture process with existing of $\mathrm{SO}_{2}$ : degradation, reaction rate, and mass transfer," Energy \& Fuels, vol. 25, no. 12, pp. 5802-5809, 2011.

[18] J. Shunxiang, Numerical and Experimental Study on Absorption of Carbon Dioxide from Flue Gas in the Hollow Fiber Membrane Contactor, Chongqing University, 2014.

[19] H. Hikita, S. Asai, and T. Tsuji, "Absorption of sulfur dioxide into aqueous sodium hydroxide and sodium sulfite solutions," AIChE Journal, vol. 23, no. 4, pp. 538-544, 1977.

[20] M. Caplow, "Kinetics of carbamate formation and breakdown," Journal of the American Chemical Society, vol. 90, no. 24, pp. 6795-6803, 1968.

[21] E. F. Da Silva and H. F. Svendsen, "Ab initio study of the reaction of carbamate formation from $\mathrm{CO}_{2}$ and alkanolamines," Industrial \& Engineering Chemistry Research, vol. 43, no. 13, pp. 3413-3418, 2004.

[22] S.-W. Park, D.-W. Park, K.-J. Oh, and S.-S. Kim, "Simultaneous absorption of carbon dioxide and sulfur dioxide into aqueous 2-amino-2-methy-1-propanol," Separation Science and Technology, vol. 44, no. 3, pp. 543-568, 2009.
[23] Z. Zhang, Y. Yan, L. Zhang, and S. Ju, "Numerical simulation and analysis of $\mathrm{CO}_{2}$ removal in a polypropylene hollow fiber membrane contactor," International Journal of Chemical Engineering, vol. 2014, Article ID 256840, 7 pages, 2014.

[24] B. R. Strazisar, R. R. Anderson, and C. M. White, "Degradation pathways for monoethanolamine in a $\mathrm{CO}_{2}$ capture facility," Energy and Fuels, vol. 17, no. 4, pp. 1034-1039, 2003.

[25] Y. Lv, X. Yu, S.-T. Tu, J. Yan, and E. Dahlquist, "Experimental studies on simultaneous removal of $\mathrm{CO}_{2}$ and $\mathrm{SO}_{2}$ in a polypropylene hollow fiber membrane contactor," Applied Energy, vol. 97, pp. 283-288, 2012. 

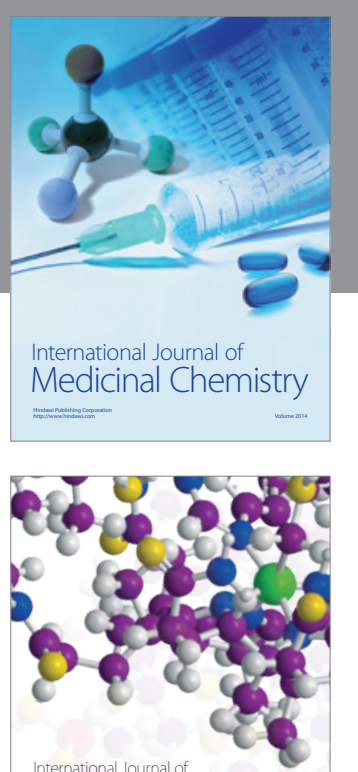

Carbohydrate Chemistry

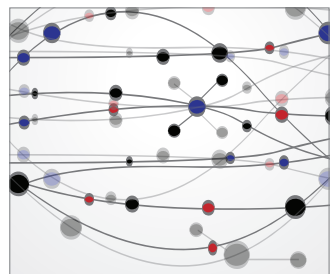

The Scientific World Journal
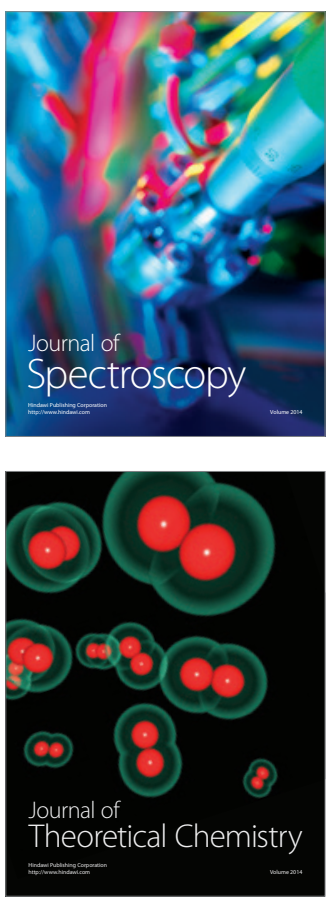
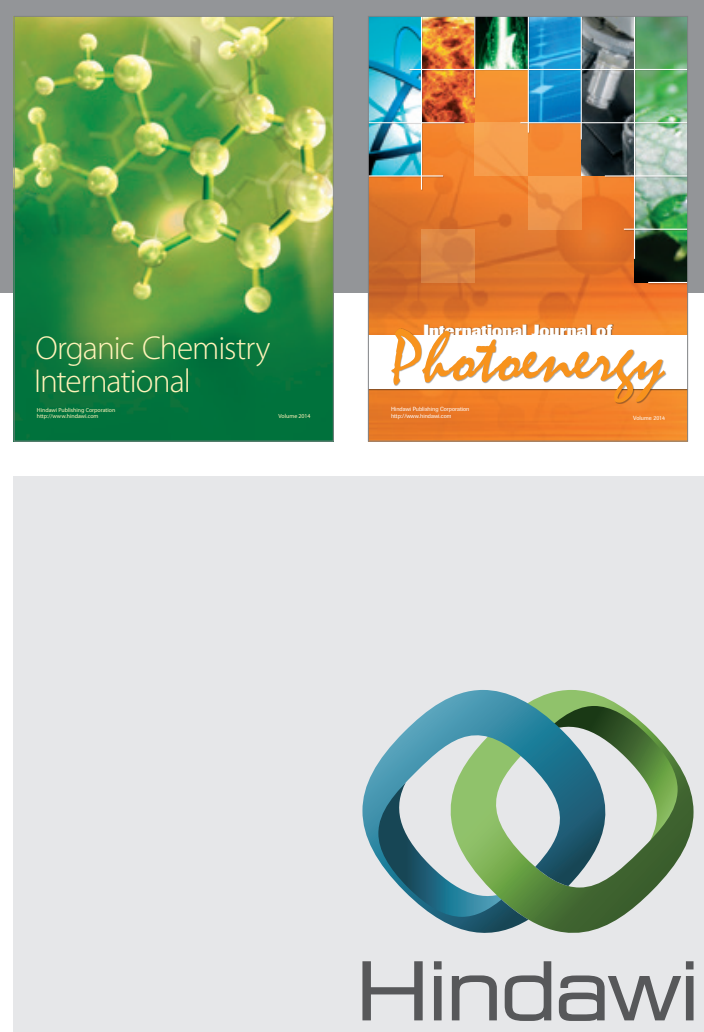

Submit your manuscripts at

http://www.hindawi.com

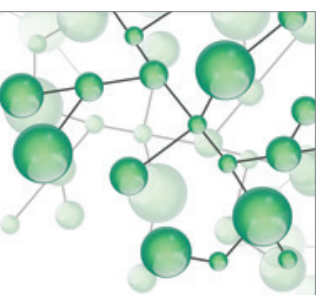

International Journal of

Inorganic Chemistry

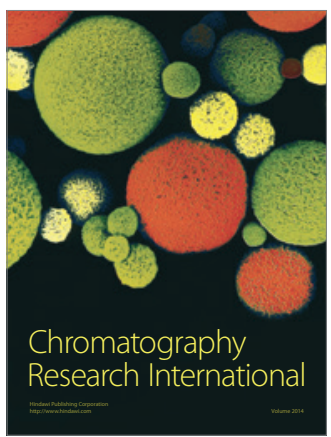

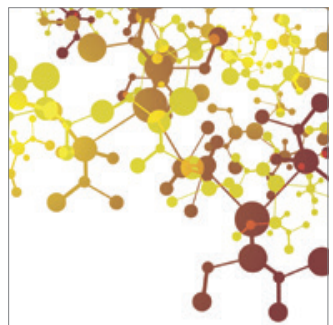

Applied Chemistry
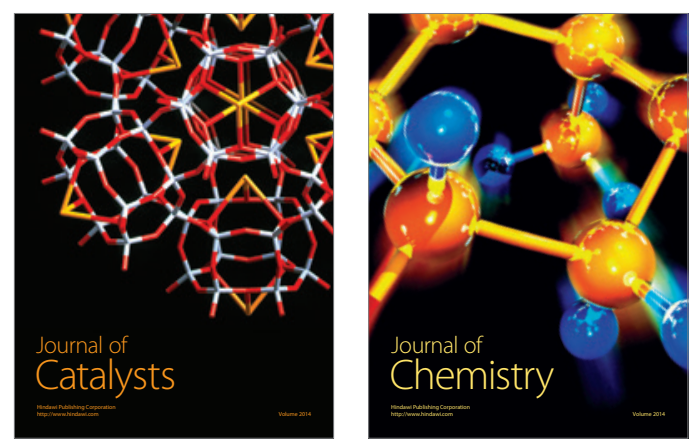
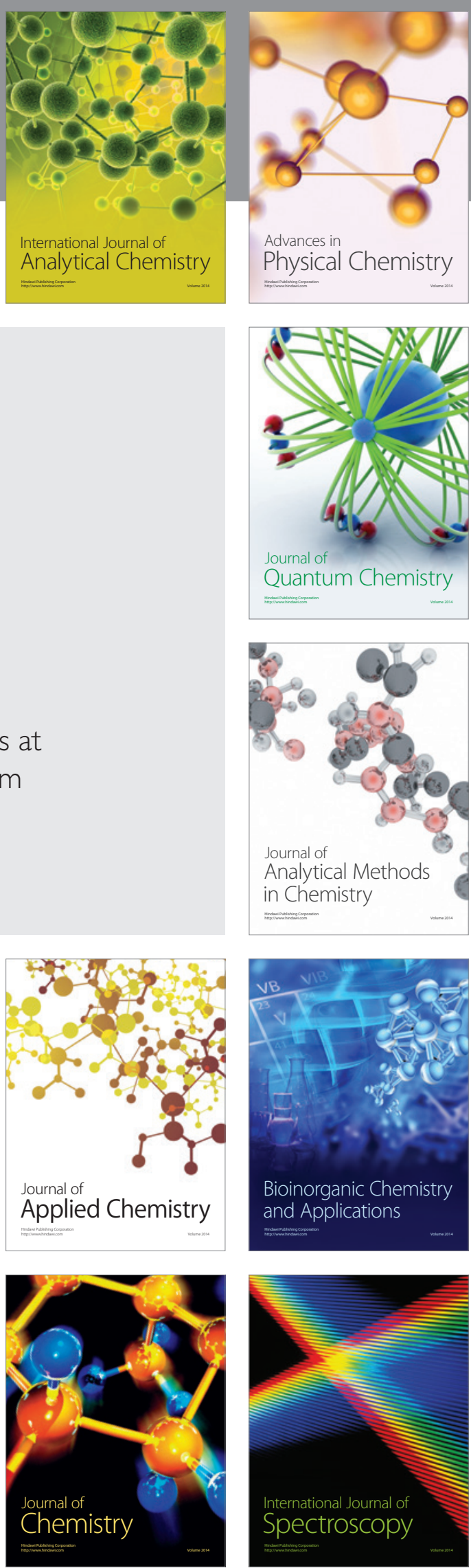